\title{
Surface albedo as a proxy for the mass balance of Greenland's terrestrial ice
}

\author{
William Colgan, Jason E. Box, Robert S. Fausto, Dirk van As, Valentina R. Barletta and Rene Forsberg
}

Satellite observations are critical to understanding the mass balance of Greenland's terrestrial ice (Fig. 1). The Gravity Recovery and Climate Experiment (GRACE) satellite constellation provides monthly gravimetry observations that can directly assess mass balance. Temporal data gaps have begun to appear in the GRACE record due to declining satellite function. In anticipation of further deterioration in the coverage of GRACE, we have explored an empirical relation between ice-surface albedo (or reflectance) and ice-mass balance to fill the gaps in the gravimetry record of Greenland's ice-mass balance. As surface albedo observed by the moderate-resolution imaging spectroradiometer (MODIS) aboard the Terra satellite is available in near real-time, employing a MODISderived proxy permits near real-time estimates of Greenland ice-mass balance. The Geological Survey of Denmark and Greenland has begun employing the albedo - mass-balance relation described here to issue near real-time estimates of Greenland ice-mass balance during the summer melt season at www.polarportal.org.

\section{Data and method}

We employ ice-mass balance data for Greenland as assessed by the Technical University of Denmark monthly GRACE RL05 solutions from the 2003 to the 2012 summer melt seasons (May to September; Barletta et al. 2013). Monthly mass balance, calculated by node-centred finite differencing of this solution time series, is available for 44 out of 50 study-period months. Single, missing monthly solutions (Jun 2003, Jun 2011 and Jul/Aug 2012) prevent resolving mass balance for the months preceding and following the missing solutions (May/Jul 2003, May/Jul 2011 and Jun/Sep 2012; Tedesco $e t$ al. 2013). The $1 \sigma$ uncertainty associated with monthly mass balance calculated in this way ranges from 45 to $149 \mathrm{Gt}$, with an average of $91 \mathrm{Gt}$ over the study period. We take this average value as representative of the uncertainty in GRACEderived monthly mass balance.

We employ the Greenland ice-surface albedo observed by Terra MODIS MOD10A1 during clear sky conditions. Clear sky conditions vary both temporally and spatially, especially in South Greenland, where c. 25\% of the MODIS scenes show clear sky. Eleven-day running statistics are used to identify and reject $<5 \%$ of the values within a given scene that exceed $2 \sigma$ from the running multi-scene mean. To prevent rejecting potentially valid cases, data within 0.04 of the running multi-scene median are not rejected (Box et al. 2012). Mean monthly albedo is generated from these clear sky and filtered scenes for the melt-season months from 2003 to 2012. We compared the MODIS monthly albedo with in situ observations from the Programme for Monitoring of the Greenland Ice Sheet (PROMICE; van As et al. 2013) and the Greenland Climate Network (Steffen \& Box 2001), and found that the root mean squared error reached a minimum of 0.039 in May and a maximum of 0.085 in September. The bias between MODIS and in situ albedo, which was less than the root mean squared error in all months, ranged from -0.027 in June to 0.022 in September. We therefore take the $1 \sigma$ uncertainty associated with the ice-sheet-wide MODIS monthly albedo to be 0.059 during the summer melt season, the average May
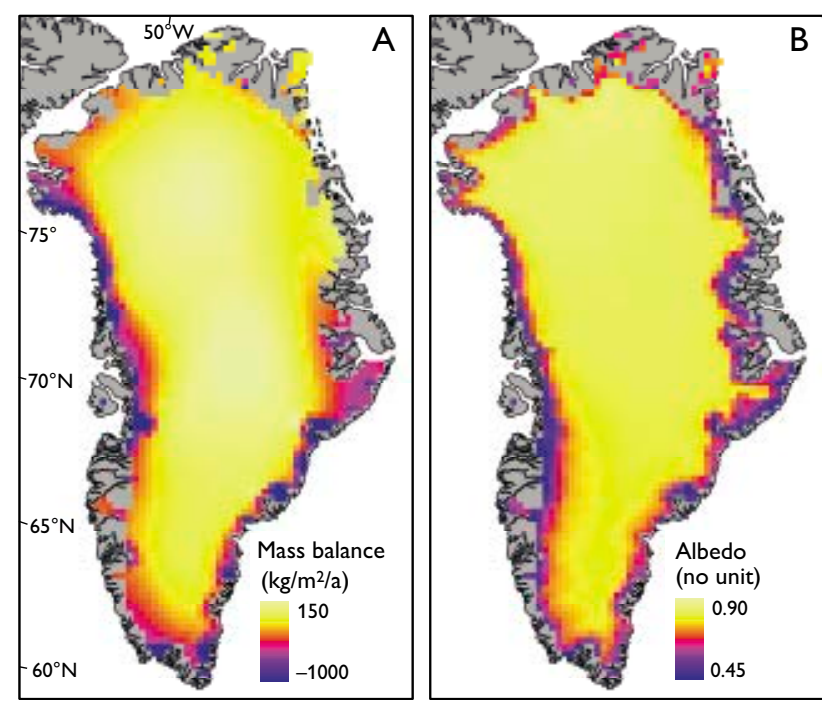

Fig. 1. A: Mean annual mass balance of Greenland's terrestrial ice, derived by an inversion of mass loss observed by satellite gravimetry that is constrained by satellite altimetry and fractional ice-coverage information (Colgan et al. 2014). B: June to August mean albedo, derived by averaging all available clear sky albedo scenes, each of which has been filtered using running statistics to reject invalid data (Box et al. 2012). Both datasets span the period from 2004 to 2010 and share a common ice mask where the local ice fraction exceeds 0.5 at $26 \mathrm{~km}$ resolution. Colour bars saturate at maximum and minimum values. 

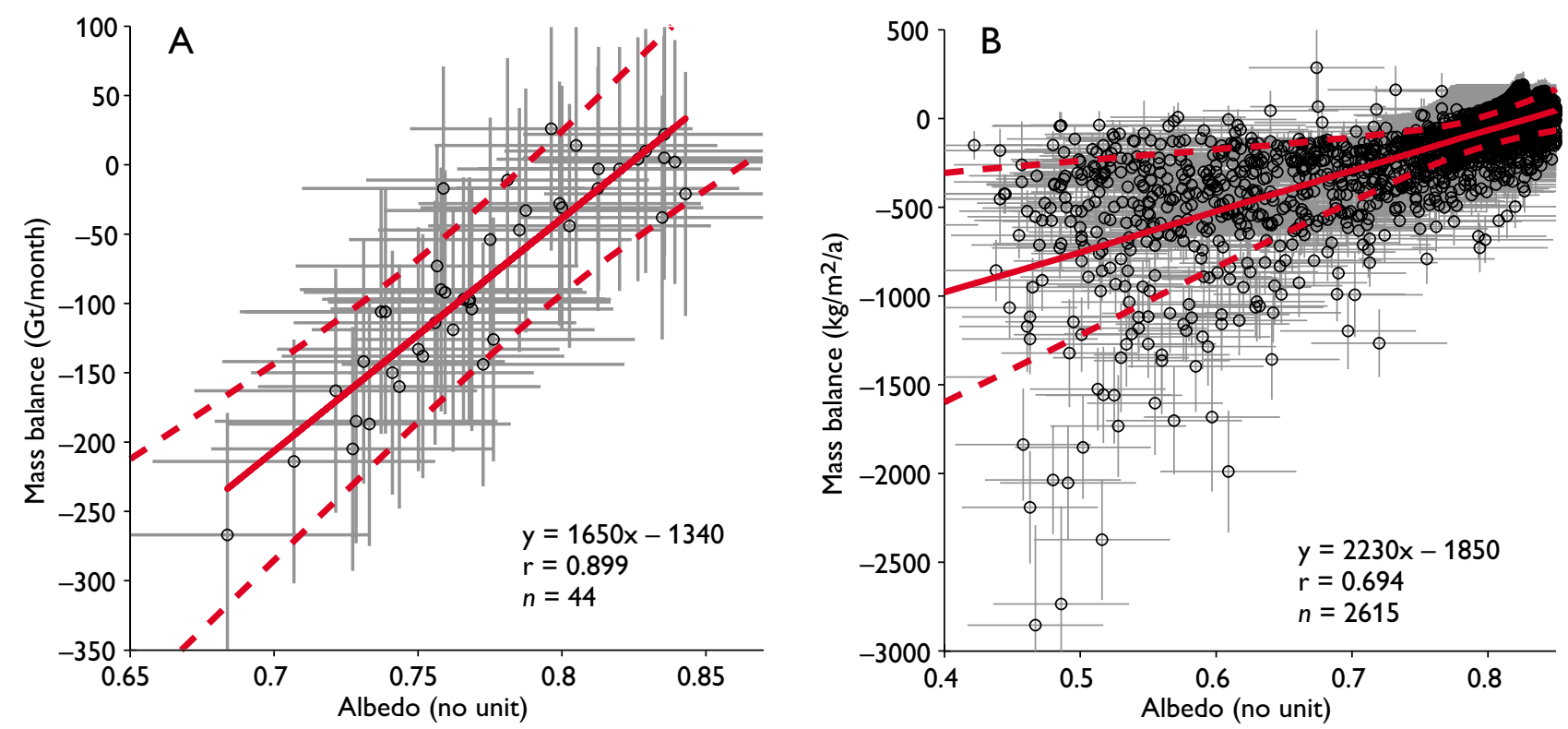

Fig. 2. Mass balance versus albedo in time and space. A: Greenland ice monthly mass balance derived from satellite gravimetry (Barletta $e t$ al. 2013) versus monthly average albedo derived from satellite imagery (Box et al. 2012), during May to September over the period from 2003 to 2012 . B: Local mean annual mass balance derived from an inversion of satellite gravimetry (Colgan et al. 2014) versus local June to August mean albedo derived from satellite imagery (Box et al. 2012), averaged over the 2004 to 2010 period and across the domain shown in Fig. 1. Solid and dashed lines denote ordinary least squares regression ( $2 \sigma$ uncertainty envelope).

through September root mean squared error between local in situ and MODIS observations. A portion of this apparent discrepancy likely results from footprint differences between in situ $\left(c .10 \mathrm{~m}^{2}\right)$ and MODIS $\left(c .500 \mathrm{~m}^{2}\right)$ albedo samples.

Using these GRACE-derived mass-balance and MODISderived albedo records, we evaluate a single variable regression model to estimate monthly mass balance as a function of monthly albedo. Monthly albedo $(\alpha)$ is strongly correlated with monthly mass balance $(\partial M / \partial t)$ during the summer melt months within the study interval $(r=0.899, p<0.01$; Fig. 2A). This implies that the Greenland ice-mass balance can be statistically approximated by

$$
\frac{\partial M}{\partial t}=A \alpha+c
$$

where $A$ is a coefficient equal to $1650 \mathrm{Gt} /$ month, and $c$ is a constant of $-1340 \mathrm{Gt} /$ month. $A$ is the apparent sensitivity of mass balance to albedo (e.g. a 0.01 decrease in monthly average albedo corresponds to a $16.5 \mathrm{Gt}$ decrease in monthly mass balance), while $c$ would be the theoretical minimum monthly mass balance when all solar radiation is absorbed (e.g. when $\alpha=0$ ).

\section{Application}

Two sources of error arise when estimating the Greenland ice-mass balance via ice-surface albedo: the statistical un- certainty associated with albedo as a proxy for mass balance, and the underlying measurement uncertainty associated with resolving monthly mass balance. The monthly Greenland ice-mass balances predicted by single variable albedo regression agree with the monthly mass balances observed by GRACE within a root mean squared error of $\pm 32 \mathrm{Gt} / \mathrm{month}$. Combining, in quadrature, this statistical uncertainty with the characteristic measurement uncertainty in the GRACE-derived Greenland ice-mass balance $( \pm 91 \mathrm{Gt} / \mathrm{month})$, yields a total uncertainty in albedo-regressed mass balance of $\pm 96 \mathrm{Gt} / \mathrm{month}$. We calculate uncertainty in, and assess stationarity of, $A$ and $c$ by calculating their values in overlapping four-year subsets of the ten-year study period. This subset analysis yields $1 \sigma$ uncertainties associated with best-fit $A$ and $c$ parameters of $1650 \pm 400$ and $-1340 \pm 300 \mathrm{Gt} /$ month, respectively. An apparent increase in $A$ and decrease in $c$ over time are suggestive of an increase in mass-balance sensitivity to albedo over time. This is consistent with indications that surface mass balance is now the dominant mechanism of Greenland ice loss (Enderlin et al. 2014). The drift in both $A$ and $c$, however, is statistically insignificant over the satellite record length presently available for analysis. Within associated statistical uncertainty, we therefore suggest that average monthly ice-surface albedo is a stationary proxy for the monthly Greenland ice-mass balance during the 2003 to 2012 melt seasons. 
The utility of ice albedo as a proxy for ice-mass balance may be evaluated by comparing GRACE- and MODIS-derived cumulative mass-balance anomalies and monthly massbalance rates. The albedo-regressed cumulative anomaly captures both the rate and magnitude of mass loss in each melt season between 2003 and 2012 (Fig. 3A). Albedo-regressed mass-balance rates, however, generally overestimate mass loss early in the melt season $(-26 \mathrm{Gt} /$ month on average in May and June), and underestimate mass loss late in the melt season $(+13 \mathrm{Gt} /$ month on average in August and September). The single largest residual is a mass-loss overestimate of -92 Gt in June 2009 (Fig. 3C). Precipitation is recognised to decrease with air temperature, as a function of temperaturedependent absolute humidity. PROMICE weather data suggest the June 2009 outlier is most likely due to anomalously cold air temperatures and little snowfall after the initiation of spring melt, which resulted in an anomalously low June surface albedo and melt rate. While cumulative anomalies compound any systematic biases over the course of a season, the magnitude and associated uncertainty of the albedoregressed, monthly mass-balance rates appear reasonable in the context of analogous GRACE values (Fig. 3B).

\section{Discussion and summary}

The mass balance of Greenland's ice reflects a combination of surface mass balance and underlying ice dynamic processes. The physical basis for surface albedo being a skilful proxy of surface mass balance is straightforward; albedo increases with fresh snowfall and decreases with melt or snowpack removal (Fig. 2B). Albedo therefore integrates the competing surface mass-balance processes of accumulation and ablation. Snow or ice albedo directly influences meltwater pro-
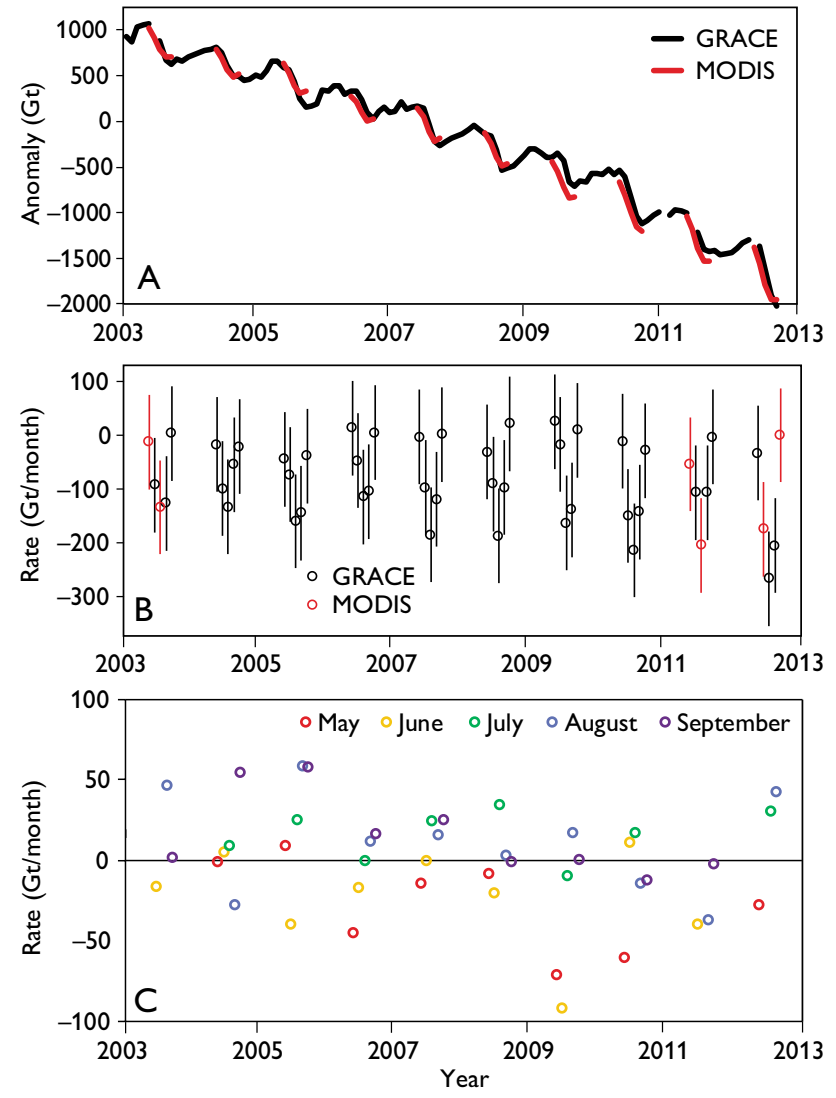

Fig. 3. A: Cumulative mass balance anomaly for Greenland's ice observed by GRACE satellite gravimetry over the period from January 2003 to October 2012 (Barletta et al. 2013), and the analogous albedo-regressed anomaly for May to September melt periods derived from MODIS satellite imagery. In each year, cumulative albedo-regressed mass loss is applied to the April anomaly assessed by Barletta et al. (2013). B: Melt season ice-mass balance rate (Barletta et al. 2013), and the analogous albedoregressed rate when GRACE-derived values are not available. C: Residual (MODIS-derived minus GRACE-derived) in monthly ice-mass balance during the May to September melt season.

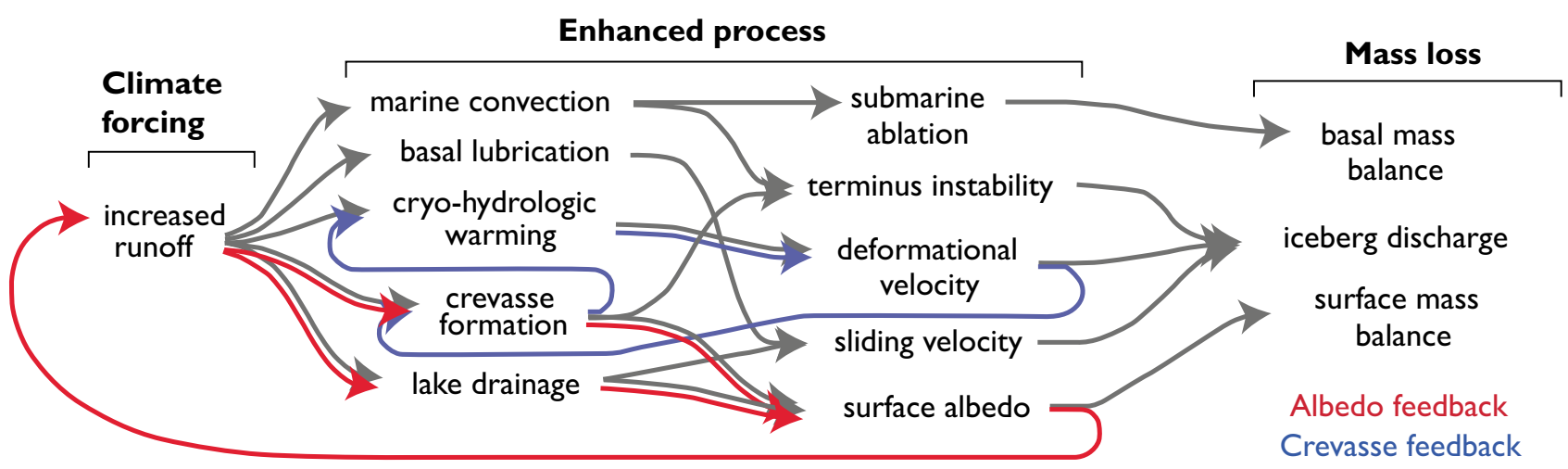

Fig. 4. Understanding the relation between surface albedo and mass balance: a schematic overview of previously recognised linkages between increased meltwater runoff and enhanced ice loss in Greenland (Box \& Colgan 2013). Many intermediate processes convert increased meltwater runoff into increased ice loss via either iceberg discharge or surface or basal mass balance. Some processes involving ice-surface albedo and crevasses form positive feedback loops, potentially amplifying mass loss (Colgan et al. 2011). 
duction and mass loss via runoff (Hock 2005). The indirect links between decreased surface albedo (and increased meltwater runoff) and enhanced mass loss via ice discharge from marine-terminating glaciers are numerous and diverse (Fig. 4; Box \& Colgan 2013). Similar to surface-balance processes, however, processes enhancing ice dynamics, such as crevasses and supraglacial lakes, also generally decrease albedo with increasing mass loss.

For example, as crevassed ice absorbs approximately twice as much solar radiation as non-crevassed ice, small changes in crevasse extent can substantially modify albedo. A $>10 \%$ increase in crevasse extent since $c$. 1998 within a West Greenland study area has been attributed to the acceleration of $\mathrm{Ja}$ kobshavn Isbræ (Colgan et al. 2011). Crevasses can facilitate dynamic mass loss via enhanced terminus instability, as well as enhanced deformational velocity resulting from cryo-hydrologic warming. Similarly, a low-albedo 'dark zone' forms in the elevation band where meltwater accumulates, both within the snow and firn, as well as in supraglacial lakes. Within this 'dark zone', up to $40 \%$ of variability in annual mass balance is due to variability in summer ice-surface albedo (Greuell 2000). In high-melt years, lakes form at higher elevations and have a higher probability of rapidly draining large water volumes to the subglacial hydrological system (Liang et al. 2012). Albedo 'dark zone' width is therefore directly proportional to the delivery of water to the ice-bed interface.

Given previously recognised strong links between albedo and surface mass balance (Hock 2005), the high correlation between Greenland ice albedo and mass balance that we have explored supports the notion that the majority of recent Greenland ice-mass loss has occurred via meltwater runoff (Enderlin et al. 2014). Given the numerous and diverse previously postulated links between increased meltwater runoff and enhanced ice-dynamic mass loss, we suggest that a substantial portion of variability in dynamic mass loss is ultimately modulated by surface albedo and meltwater runoff (Box \& Colgan 2013). The overarching inference from our preliminary data exploration is that a strong relation exists between Greenland's ice-surface albedo and mass balance, both through time and across space, and this merits further examination (Fig. 2). As near real-time albedo monitoring has proved successful in qualitatively forecasting extreme Greenland ice-mass loss events (Box et al. 2012), the Geological Survey of Denmark and Greenland has begun employing the albedo regression described here to issue near real-time estimates of Greenland ice-mass balance during the melt season at www.polarportal.org (Fausto et al. 2013).

\section{Acknowledgement}

This work is supported by the Danish Council for Independent Research, Natural Sciences (11-115166) and PROMICE.

\section{References}

Barletta, V.R., Sørensen, L.S. \& Forsberg, R. 2013: Scatter of mass changes estimates at basin scale for Greenland and Antarctica. The Cryosphere 7, 1411-1432.

Box, J., Fettweis, X., Stroeve, J.C., Tedesco, M., Hall, D.K. \& Steffen, K. 2012: Greenland ice sheet albedo feedback: thermodynamics and atmospheric drivers. The Cryosphere 6, 821-839.

Box, J. \& Colgan, W. 2013: Greenland Ice Sheet mass balance reconstruction. Part III: Marine ice loss and total mass balance (1840-2010). Journal of Climate 26, 6990-7002.

Colgan, W., Steffen, K., McLamb, W.S, Abdalati, W., Rajaram, H., Motyka, R.J., Phillips, T. \& Anderson, R.S. 2011: An increase in crevasse extent, West Greenland: Hydrologic implications. Geophysical Research Letters 38, L18502.

Colgan, W., Abdalati, W., Citterio, M., Csatho, B., Fettweis, X., Luthcke, S., Moholdt, G. \& Stober, M. 2014: Hybrid inventory, gravimetry and altimetry (HIGA) mass balance product for Greenland and the Canadian Arctic. The Cryosphere Discussions 8, 537-580.

Enderlin, E.M., Howat, I.M., Jeong, S., Noh, M.-J., van Angelen, J.H. \& van den Broeke, M.R. 2014: An Improved Mass Budget for the Greenland ice sheet. Geophysical Research Letters 41, 866-872.

Fausto, R.S., Colgan, W. \& Langen, P.L. 2013: Real-time changes in Arctic ice presented in online portal. EOS, Transactions of the American Geophysical Union 94, 397-398.

Greuell, W. 2000: Melt-water accumulation on the surface of the Greenland ice sheet: effect on albedo and mass balance. Geografiska Annaler 82A, 489-498.

Hock, R. 2005: Glacier melt: a review of processes and their modelling. Progress in Physical Geography 29, 362-391.

Liang, Y.-L., Colgan, W., Qin, L, Steffen, K., Abdalati, W., Stroeve, J., Gallaher, D. \& Bayou, N. 2012: A decadal investigation of supraglacial lakes in West Greenland using a fully automatic detection and tracking algorithm. Remote Sensing of Environment 123, 127-138.

Steffen, K. \& Box, J. 2001: Surface climatology of the Greenland ice sheet: Greenland climate network 1995-1999. Journal of Geophysical Research 106, 33 951-33964.

Tedesco, M., Fettweis, X., Mote, T., Wahr, J., Alexander, P., Box, J.E. \& Wouters, B. 2013: Evidence and analysis of 2012 Greenland records from spaceborne observations, a regional climate model and reanalysis data. The Cryosphere 7, 615-630.

Van As, D., Fausto, R.S., Colgan, W.T., Box, J.E. and the PROMICE project team 2013: Darkening of the Greenland ice sheet due to the meltalbedo feedback observed at PROMICE weather stations. Geological Survey of Denmark and Greenland Bulletin 28, 69-72.

\footnotetext{
Authors' address es

W.C., J.E.B., R.S.F. \& D.v.A., Geological Survey of Denmark and Greenland, Øster Voldgade 10, DK-1350 Copenhagen K, Denmark. E-mail: wic@geus.dk V.R.B. \& R.F., Technical University of Denmark DK-2800 Kgs. Lyngby, Denmark.
} 